\title{
Supplier Selection Under Fuzzy Environment
}

\author{
Çağdaş Gündüz ${ }^{1}$, Gonca Şimşek Gündüz ${ }^{2}$ * \\ ${ }^{1}$ Pamukkale University, School of Applied Sciences, Denizli, Turkey; \\ ${ }^{2}$ Pamukkale University, Denizli Vocational School of Technical Sciences, Denizli, Turkey
}

Corresponding Author: Çağdaş Gündüz, cgunduz@pau.edu.tr

\begin{abstract}
Selecting the right supplier in supply chain is of great importance for firms. Because, when the supplier is a piece of a well-organized supply chain, this relationship may affect the competition power across the entire supply chain. Supplier selection is so critical process that it requires to evaluate many factors likequality, delivery time, cost, technology, payment due, flexibility andcorporate reputation. Decision makers must consider these factors to select ideal suppliers. At this point, multi-criteria decision making methods (MCDM) help them to solve supplier selection problems. In this paper, considering the fuzziness in group decision making process, fuzzy set theory is used to deal with supplier selection problem of textile manufacturing firm. Ratings and weights of the criteria are expressed by linguistic variables. According to the proposed method fuzzyTechnique for Order Preference by Similarity to Ideal Solution (TOPSIS), a closeness coefficient is calculated for obtaining supplier performance rankings.
\end{abstract}

\author{
ARTICLE HISTORY \\ Received: 10.04.2019 \\ Accepted: 21.08.2019
}

\section{KEYWORDS}

supplier selection, supply chain, fuzzy TOPSIS method, linguistic variables, MCDM

\section{INTRODUCTION}

The meaning of being a supplier for firms has changed in today's market conditionswhere competition takes place among the supply chains. Firms desire to construct longterm relations based on mutual trustwith their stakeholders like suppliers. Since, to work with the right supplier can reduce purchasing costs for the firm and can increase customer satisfaction. In this way, the firm is able to gain a chance to strength it's competitiveness and performance $[1,2]$. Therefore, supplier selection process is of great importance for firms in today's global market conditions and firms must achieve this processeffectively for their future. Firms also must be flexible against changing market conditions and customer demands. A wellorganized supply chain management helps firms to realize these goals. Because, supply chain management controls whole products and information flowing through the supply chain of the firm. It is a process which involves the firm's selection of a supplier for its' production operations. In other words, supplier selection targets to select the supplier with the highest potential for meetingdemands of a firm at an acceptable cost. The most important topic here is to construct the closeness and long term reliable relations with the optimal supplier among a number of suppliers [3-5]. To select a supplier is one of most difficult and critical decisions forthe buyer because it has some factors in it. Also, these factors may differ according to firm's needs. If the firm wants to complete this selection in an effective way, so it evaluates many criteria [6]. Among those criteria considered by decisionmakers in supplier selection, quality, delivery time, cost, production capability, service management, technology, research and development, finance, flexibility, reputation and risk are the most popular ones. As it is seen, it may involve different types of criteria, various decision models to select a supplier so it is a multicriteria decision problem for the firm [7].

The supplier selection process covers different steps. First of all, the firm requires a new supplier so it is very important for the firm to expose exactly what it wants to achieve in supplier selection problem. Secondly, the firm should decide on selection criteria in accordance with its own needs and also it has adequate knowledge about alternatives. Third, the firm should select the one that meets the needs at the maximum level among the alternatives [8]. Briefly, it is very difficult to find the best way for the firm to eliminate alternatives and select supplier because it is required to use a variety of different methods forachieving

To cite this article: Gündüz Ç, Gündüz GŞ. 2019. Supplier selection under fuzzy environment, Tekstil ve Konfeksiyon 29(4), 344-352. 
it. So, the main issue in this process is to find the most appropriate method among many selection methods to select the ideal supplier.

Actually, the supplier selection problem is the process of finding the best option among all suitable alternatives. When firms make an effort to find the ideal option, they should be cared forthe number of alternatives and decision makers, the degree of uncertainty and enviromental conditions effecting criteria [9]. By means of MCDM methods, decision makerscanreach the ideal solution. For instance, MAXMIN, MAXMAX, AHP, TOPSIS, SMART, ELECTRE are the most known methods among these methods. While information technologies are developing rapidly, the usage of computers have become widespread so these methods have found great acceptance in selecting suppliers [10]. But, there may exist some differences between methods in solving problems. The ratings and the weights of criteria are measured exactly in classical MCDM models. In other words, those kind of models assume precise data $[11,12]$. However, human judgments cannot be predicted with precise numerical values. Also, they are often uncertain. For this reason, the exact data will not be sufficient to model real life conditions under many circumstances $[13,14]$. For example, decision makers set to decide under time pressure or limited knowledge capacity. In this situation, the use of linguistic variables instead of numerical values can be a more realistic approach. The ratings and weights of the criteria may be expressed by linguistic variables [15, 16]. According to Zadeh [17], a linguistic variable isa variable that is expressed in words or sentences in natural or artificial language. Language variables are also expressed statements like very high, very good, high, good, normal, very low, very bad [18]. According to Saghafian and Hejazi (2005) [19], this kind of linguistic expressions are a natural representation of human judgments. These characteristics represent the feasibility of fuzzy set theory of Zadeh in constructing the decision maker's preferred structures. The fuzzy set theory is related with the human's ability to understand and analyze inaccurate information. Zadeh developed it based on the idea that the key elements of human thought are linguistic expressions rather than numbers $[16,17]$.

Fuzzy set theory helps to measure the uncertainty in concepts through the subjective judgments of human beings $[19,20]$. To Bellman and Zadeh [21], a fuzzy set is a class of objects in which there is no sharp boundary between those objects in terms of being member or non-member. From this point, the classes of objects can be characterized by some adjectives that are commonly used as large, small, important, serious, simple, accurate, approximate. The theory models linguistic uncertainty related to human perception and subjective judgment. It provides the interpretation of qualitative parameters and mathematical expression of linguistic uncertainty with fuzzy numbers [22].

Fuzzy set theory applications are increasing day by day in the solution of uncertain fuzzy problems by means of Zadeh's fuzzy set theory in 1975 and also Bellman and
Zadeh's decision-making methods in fuzzy environments in 1970 [18].

Supplier selection process have received great attention in the supply chain management literature recently. When the literature is examined, it is seen that there are various studies on both supplier selection and fuzzy TOPSIS method. Chen, Lin and Huang (2006) [9] developed a model to cope with the supplier selection problem of a high technology manufacturing company based on the concept of fuzzy TOPSIS method. They used the linguistic variables in order to assess the ratings and weights for the supplier evaluating factors. These linguistic variables were expressed in both trapezoidal and triangular fuzzy numbers. By applying the fuzzy TOPSIS, they calculated closeness coefficient of each supplier and selected the suitable supplier for the company.

Zouggari and Benyoucef's (2012) [23], study is conducted by using both supplier selection and fuzzy TOPSIS method. The criteria required is quantitatively evaluated for order allocation among the selected suppliers in the study. Fuzzy TOPSIS is applied to determine the weights for order allocation. Singh and Benyoucef (2012) [24], proposed the use of fuzzy TOPSIS for group decision making method to select the best supplier among several alternatives.

Orji and Wei (2014) [25], considered the importance of sustainability in supplier selection process to improve organizational performance in one of Chinese gear manufacturing company. In the study, the researchers developed a model based on integrated MCDM methods to solve supplier selection problem. TOPSIS methodology which is the most preferred for capturing all objective and subjective criteria is applied to choose the best possible sustainable supplier in fuzzy environment. Then, they analyzed the interdependencies between some sustainability factors including social, economic and environmental factors. And then, they tried to select the best sustainable supplier in fuzzy environment effectively. The findings demonstrated that the company considered frequently on work safety and quality factors of the respective suppliers.

Kannan, Jabbour, and Jabbour (2014) [26], used fuzzy TOPSIS method to select the most suitable supplier among a set of potential green suppliers for a Brazilian electronic company. They ranked the suppliers. The results of the proposed framework are compared with the ranks obtained by both the geometric mean and the fuzzy TOPSIS methodology. In order to examine the influence of preferences given by stakeholders as decision makers about selecting various suppliers a sensitivity analysis has been performed.

Igoulalene, Benyoucef and Tiwari (2015) [27], addressed the strategic supplier selection problem. They formulated the supplier selection problem as a fuzzy multi criteria decision making problem and solved it by using one of two approaches including fuzzy TOPSIS methodology. They computed the weights of the criteria for fuzzy TOPSIS. To show the applicability of this methodology, they presented 
a simple supplier selection problem and analyzed numerical results. Finally, they listed the advantages and disadvantages of each approach they used in the study.

Other studies using TOPSIS, which is a frequently used model in supplier selection, can be listed as Wang, Cheng and Cheng (2009) [28]; Razmi, Songhori and Khakbaz (2009) (29); Shahanaghi and Yazdian (2009) [30]; Liao and Kao (2011) [31]; Li and Zabinsky (2011) [32]; Rouyendegh and Saputro (2014) [33]. All of these studies cope with the supplier selection problem to make a judgment about optimum supplier among the other alternatives by applying fuzzy TOPSIS methodology. The ideal supplier selection is obtained by integrating the closeness coefficients to the fuzzy TOPSIS model. In the end, the supplier who received the top ranking is defined as the optimum supplier.

TOPSIS method is one of the most frequently used method to select appropriate supplier the literature. But, the uncertainty effect upon decision criteria is the main problem for this method. In this paper, considering the fuzziness in group decision making process, we used fuzzy set theory.

The paper aims to evaluate the supplier selection problem of a textile manufacturing firm by using the fuzzy TOPSIS method. The paper is formed four sections. Next section gives some details about the fuzzy decisionmakingmethod to deal with the supplier selectionproblem in the study. In section 3, the proposed method isillustrated with an example. Finally, some conclusionsare pointed out at the end of the paper.

\section{MATERIAL AND METHOD}

TOPSIS method proposed by Hwang and Yoon (1981) [12] is one of the well known methods in the literature for MCDM. This method was later developed by some authors like Chen (2000) [15], Zavadskas, Turskis and Tamosaitiene (2008) [34], Hung and Chen (2009) [35]. The main point of TOPSIS is to identify the ideal solution which consists of all of best values accessible of criteria and the negative ideal solution which is composed of all worst values accessible of criteria [36]. In other words, unlike other methods, TOPSIS is based on logical thinking which gives the most appropriate results for both the positive ideal solution and the negative ideal solution. According to Hung and Chen (2009) [35]; Bottani and Rizzi (2006) [37], compared to other MCDM methods, TOPSIS has some advantages. Some of these advantages can be explained as being rational and simple, efficiency in computation, flexibility in ranking of alternatives and to calculate the best and worst alternatives ability for measuring the relative performance of alternatives in a simple mathematical form.

In addition to these aforementioned positive aspects of TOPSIS method, a different method called the Fuzzy TOPSIS is used in order to prevent the negative conditions caused by the changes in the decision criteria against some changes in environmental conditions and uncertainty especially. The basis of the fuzzy TOPSIS method is that the decision criteria used by decision makers to evaluate alternatives have different weights. Using the fuzzy TOPSIS method, the decision coefficients and their evaluations about alternatives are converted into triangular or trapezoidal fuzzy numbers. Then the proximity coefficient of each alternative is calculated [9]. In classical TOPSIS, the rating and weight of the criteria are known precisely. In fuzzy TOPSIS, all the ratings and weights are defined by means of linguistic variables [10, 38, 39]. If it is decided to use fuzzy TOPSIS instead of TOPSIS, a number of weaknesses can be eliminated. Firstly, results may fail to comply with basic considerations sometimes. In this case, the best solution is the closest option to the positive ideal solution and the uttermost option to the negative ideal solution. Secondly, in fuzzy TOPSIS method, it is required for each criterion to assign initial weight for calculation. Finally, when fuzzy numbers are 1 and 0 , it is directly assumed that they are both positive ideal solution and negative ideal solution. When the weights of criteria are extremely small, the closeness between the criteria and fuzzy positive and negative ideal solutions increase [38].

It is understood from the aforementioned statements that fuzzy TOPSIS is suitable for decision making in fuzzy environments where uncertainty prevails. Membership functions are given to linguistic expressions by using fuzzy numbers, thus uncertainty is eliminated. Theselinguistic expressions are most commonly expressed in triangular or trapezoidal fuzzy numbers [9]. The degree of membership for a continuous variable is expressed by the membership function and it is determined subjectively [38]. The membership function grade approaches 1 as the degree to which an element belongs to a certain set increases, otherwise it approaches 0 in the fuzzy set theory [3]. Because of the linear simple membership function, Hanns (2005) [40] stated thatthe use of triangular fuzzy numbers is generally preferred. Sanchez and Gomez (2003) [41] expressed that triangular fuzzy numbers are most commonly used fuzzy numbers because they provide ease of operation and also they can be created intuitively. Therefore, to avoid complexity of operations, the calculations were made using triangular fuzzy numbers in the study.

For example, if $n_{\mathbf{z}}=n_{\mathbf{3}}$ in a trapezoidal fuzzy number $n=$ $\left(n_{1}, n_{2}, n_{1} 3, n_{1} 4\right)$, then the new number $n$ is occured and called triangular fuzzy number. Given any two positive fuzzy numbers called $m$ and $n$ and a positive real number $r$, $m_{l}^{a}$ and $n_{l}^{a}$ is the lower limit of range, $m_{u}^{a}$ and $n_{u \text { is }}^{a}$ the upper limit of range, the $\alpha$-cut of two fuzzy numbers are $m^{a}=\left[m_{l}^{a}, m_{u}^{a}\right]$ and $n^{\top} a=\left[n_{\downarrow} l^{\top} a, n_{\Downarrow} u^{\uparrow} a\right](\alpha \in[0 ; 1])$, respectively. Some main operations made using triangular fuzzy numbers $m$ and $n$ can be summarized as follows [9, 15, 42]: 


$$
\begin{aligned}
& (m(+) n)^{a}=\left[m_{l}^{a}+n_{l}^{a}, m_{u}^{a}+n_{u}^{a}\right] \\
& (m(-) n)^{a}=\left[m_{l}^{a}-n_{u}^{a}, m_{u}^{a}-n_{l}^{a}\right] \\
& (m(.) n)^{a}=\left[m_{l}^{a} \cdot n_{l}^{a}, m_{u}^{a} \cdot n_{u}^{a}\right] \\
& (m(:) n)^{a}=\left[m_{l}^{a} / n_{u}^{a}, m_{u}^{a} / n_{l}^{a}\right] \\
& \left(m^{a}\right)^{-1}=\left[1 / m_{u}^{a}, 1 / m_{l}^{a}\right] \\
& (m(.) r)^{a}=\left[m_{l}^{a} \cdot r, m_{u}^{a} \cdot r\right] \\
& (m(:) r)^{a}=\left[m_{l}^{a} / r, m_{u}^{a} / r\right] \\
& \Psi_{i j}=\frac{1}{k}\left[\tilde{x}_{i j}^{1} \oplus \tilde{x}_{i j}^{2} \oplus, \ldots \ldots, \oplus \tilde{x}_{i j}^{k}\right] \\
& W_{j}=\frac{1}{k}\left[\mathscr{W}_{i j}^{1} \oplus \mathscr{w}_{i j}^{2} \oplus, \ldots . ., \oplus \tilde{W}_{i j}^{k}\right]
\end{aligned}
$$

The fuzzy TOPSIS method has some computational steps which is summarized as follows [9, 15, 43, 44]:

Step 1. Determine the objectives, form decision makers group and then identify the evaluation criteria.

Step 2. Choose the linguistic variables according to the importance of the criteria and the linguistic ratings for alternatives.

Step 3. Weights of criterion are aggregated to obtain aggregated fuzzy weight $W_{j}$ of $C_{j}$ criterion. Get aggregated fuzzy ratings $x_{i j}$ of alternative $A_{i}$ under criterion $C_{i j}$ in the opinion of decision makers.

Step 4. Construct the fuzzy decision matrix and calculate the normalized fuzzy decision matrix for each decision maker. Linguistic variables in the fuzzy decision matrix are defined as triangular fuzzy numbers

$$
\left[x_{i j}=\left(a_{i j}, b_{i j}, c_{i j}\right) w_{i j}=\left(w_{j 1}, w_{j 2}, w_{j 3}\right)\right] \text {. }
$$

Here, the various criteria scales transform into comparable scales for avoiding complexity of mathematical operations in decision process. For this reason, the set of criteria can be divided into benefit (B) and cost (C) criteria. Therefore, the normalized fuzzy decision matrix can be represented under $\mathrm{B}$ and $\mathrm{C}$ criteria as:

$$
\begin{aligned}
& \tilde{r}_{i j}=\left(\frac{a_{i j}}{c_{j}^{*}}, \frac{b_{i j}}{c_{j}^{*}}, \frac{c_{i j}}{c_{j}^{*}}\right), j \in B \\
& \tilde{r}_{i j}=\left(\frac{a_{j}^{-}}{c_{i j}^{*}}, \frac{a_{j}^{-}}{b_{i j}^{*}}, \frac{a_{j}^{-}}{a_{i j}^{*}}\right), j \in C \\
& c_{j}^{*}=\max _{i} c_{i j} \text { if } j \in B \\
& a_{j}^{-}=\min _{i} a_{i j} \text { if } j \in C
\end{aligned}
$$

Step 5. Construct weighted fuzzy decision matrix as:

$$
\tilde{v}_{i j}=r_{i j} \otimes w_{j}
$$

Step 6. Determine the positive ideal and negative ideal solutions for each decision maker.

$$
\begin{aligned}
& \nabla_{j}^{*}=(1,1,1) \\
& \nabla_{j}^{\exists}=(0,0,0)
\end{aligned}
$$

Step 7. Calculate the distance of each alternative from the positive ideal solution and thenegative ideal solution.

$$
\begin{aligned}
& d_{i}^{*}=\sum_{j=1}^{n} d\left(\nabla_{i j}, \nabla_{j}^{*}\right), i=1,2, \ldots \ldots \ldots, m \\
& d_{i}^{-}=\sum_{j=1}^{n} d\left(v_{i j}, \nabla_{j}^{*}\right), i=1,2, \ldots \ldots \ldots, m
\end{aligned}
$$

where $d_{v}(.,$.$) is the measurement of distance between two$ fuzzy numbers.

Step 8. Calculate the closeness coefficient of each alternative.

This coefficient shows the distances to the fuzzy positive ideal solution $\left(A^{*}\right)$ and fuzzy negative ideal solution $\left(A^{-}\right)$ synchronously by taking therelative closeness to the fuzzy positive ideal solution [9]. In other words, it is defined to set the ranking order of whole alternatives. The coefficient $\left(C C_{i}\right)$ is calculated for each alternative as follows:

$$
C C_{i}=\frac{d_{i}^{-}}{d_{i}^{*} \oplus d_{i}^{-}}, i=1,2, \ldots \ldots ., m
$$

Step 9. Rank the preference order for each alternative according to the closeness coefficient.

This empirical study evaluates the supplier selection problem of a textile manufacturing firm operating in Denizli by using the fuzzy TOPSIS method at first. Secondly, some advices are given to the managers about the results of this selection process. Four companies (alternatives) which are supplying knitted fabric and sewing yarn to the company in the study were evaluated. Two meetings were realized with procurement, production and marketing managers of the company. In the first meeting, managers were provided information on the supplier selection criteria in the literature. Company managers indicated cost (C1), payment due (C2), discount (C3), quality (C4), healthy product (C5), having quality certificate (C6), delivery time (C7), flexibility for changing in orders (C8), flexibility for delivery time (C9), easy contact (C10) and problem solving capability(C11) as the importance criteria in supplier selection process as a result of the first meeting. In the second meeting, managers were informed about the scales used in the evaluation of the criteria and alternatives. Then, they were asked to fill in the prepared questionnaire. Seven-point Likert scale (1= "very low (very poor)" to $7=$ "very high (very good))" was used to measure all items in the questionnaire. In this study, the questionnaires were sent through e-mail to the procurement manager, production manager and marketing manager of the surveyed textile firm. These three managers who are directly responsible for supply chain management of the firm evaluated the four suppliers separately. The questionnaire was administered in Turkish. The responses 
were collected from March to April in 2018. Finally, Microsoft Excel2007 was used for evaluating data.

\section{RESULTS AND DISCUSSION}

TOPSIS is widely used in many different areas in MCDM problems. In this paper, TOPSIS method proposed by Chen (2000) [15] was used to assist the top management of the firm to solve the supplier selection problem under a fuzzy environment.

The importance weights of each criteria presented in Table 1 as linguistic variables are assessed by three department managers as decision makers. The decision makers also use the linguistic rating variables, which is presented in Table 2 to assess ratings of alternatives with respect to each criteria.

Table 1. Linguistic variables for the importance weight of each criteria

\begin{tabular}{ll}
\hline Very low & $(0,0,0.1)$ \\
Low & $(0,0.1,0.3)$ \\
Medium low & $(0.1,0.3,0.5)$ \\
Medium & $(0.3,0.5,0.7)$ \\
Medium high & $(0.5,0.7,0.9)$ \\
High & $(0.7,0.9,1.0)$ \\
Very high & $(0.9,1.0,1.0)$ \\
\hline
\end{tabular}

Table 2. Linguistic variables for ratings

\begin{tabular}{ll} 
Very poor & $(0,0,1)$ \\
Poor & $(0,1,3)$ \\
Medium poor & $(1,3,5)$ \\
Fair & $(3,5,7)$ \\
Medium good & $(5,7,9)$ \\
\hline
\end{tabular}

$\begin{array}{ll}\text { Good } & (7,9,10) \\ \text { Very good } & (9,10,10)\end{array}$

As stated in previous part, a supplierselection problem discussed in this study in other words a MCDM problem can be expressed briefly in matrix format as follows [15]:

$$
\begin{aligned}
& \begin{array}{llll}
C_{1} & C_{2} & \ldots & C_{n}
\end{array} \\
& A_{1}\left[\begin{array}{llll}
x_{11} & x_{12} & \ldots & x_{1 n}
\end{array}\right] \\
& A_{2}\left[\begin{array}{cccc}
x_{21} & x_{22} & \ldots & x_{2 n} \\
\vdots & \vdots & \vdots & \vdots
\end{array}\right. \\
& D=A_{m}\left[\begin{array}{llll}
x_{m 1} & x_{m \mathbf{2}} & \ldots & x_{m n}
\end{array}\right] \\
& W=\left[\begin{array}{llll}
w_{1}, & w_{2} & \ldots & w_{n}
\end{array}\right],
\end{aligned}
$$

Where $x_{i j}(\forall i, j)$ and $w_{j},(j=1,2, \ldots, n)$ are linguistic variables, $\left(A_{1}, A_{2}, \ldots, A_{3}\right)$ are possible alternatives, $\left(C_{1}, C_{2}, \ldots, C_{3}\right)$ are decision criteria, $w_{j}$ is the weight of criterion $C_{j}$ and $x_{i j}$ is the rating of alternative $A_{i}$ with respect to criterion $C_{j}$. These linguistic variables can be expressed by triangular fuzzy numbers as $x_{i j}=\left(a_{i j}, b_{i j}, c_{i j}\right)$ and $w_{j}=\left(a_{j 1}, b_{j z}, c_{j 3}\right)$. Dmatrix is called fuzzy decision matrix and $W$ matrixis called fuzzy weights matrix. As a result of the questionnaire forms

\begin{tabular}{|c|c|c|c|c|c|c|c|c|c|c|c|}
\hline & C1 & $\mathrm{C} 2$ & C3 & $\mathrm{C4}$ & C5 & C6 & C7 & C8 & C9 & $\mathrm{C10}$ & C11 \\
\hline & 2,6667 & 7,6667 & 6,0000 & 2,6667 & 3,3333 & 7,6667 & 6,6667 & 3,0000 & 2,6667 & 7,3333 & 2,0000 \\
\hline Alter & 3,6667 & 8,6667 & 7,0000 & 3,6667 & 4,3333 & 8,6667 & 7,6667 & 4,0000 & 3,6667 & 8,3333 & 3,0000 \\
\hline & 3,6667 & 8,6667 & 7,6667 & 3,6667 & 4,6667 & 8,6667 & 8,0000 & 4,0000 & 3,6667 & 8,3333 & 3,3333 \\
\hline & 4,6667 & 9,6667 & 8,6667 & 4,6667 & 5,6667 & 9,6667 & 9,0000 & 5,0000 & 4,6667 & 9,3333 & 4,3333 \\
\hline & 7,6667 & 6,0000 & 2,6667 & 3,3333 & 7,6667 & 6,6667 & 3,0000 & 2,6667 & 7,3333 & 00 & 00 \\
\hline Altern & 8,66 & 7,0000 & 3,6667 & 4,3333 & 8,6667 & 7,6667 & 4,0000 & 3,6667 & 33 & 00 & 4,0000 \\
\hline \multirow[t]{2}{*}{ ? } & 8,6667 & 7,6667 & 3,6667 & 4,6667 & 8,6667 & 8,0000 & 4,0000 & 3,6667 & 8,3333 & 33 & 4,0000 \\
\hline & 9,6667 & 8,6667 & 4,6667 & 5,6667 & 9,6667 & 9,0000 & 5,0000 & 4,6667 & 9,3333 & 4,3333 & 5,0000 \\
\hline & 6,0000 & 2,6667 & 3,3333 & 7,6667 & 6,6667 & 3,0000 & 2,6667 & 7,3333 & 2,0000 & 3,0000 & 3,0000 \\
\hline Alterna & 7,0000 & 3,6667 & 4,3333 & 8,6667 & 7,6667 & 4,0000 & 3,6667 & 8,3333 & 3,0000 & 4,0000 & 4,0000 \\
\hline & 7,6667 & 3,6667 & 4,6667 & 8,6667 & 8,0000 & 4,0000 & 3,6667 & 8,3333 & 3,3333 & 4,0000 & 4,3333 \\
\hline & 8,6667 & 4,6667 & 5,6667 & 9,6667 & 9,0000 & 5,0000 & 4,6667 & 9,3333 & 4,3333 & 5,0000 & 5,3333 \\
\hline \multirow{4}{*}{$\begin{array}{l}\text { Alternative } \\
\qquad 4\end{array}$} & 2,6667 & 3,3333 & 7,6667 & 6,6667 & 3,0000 & 2,6667 & 7,3333 & 2,0000 & 3,0000 & 3,0000 & 7,3333 \\
\hline & 3,6667 & 4,3333 & 8,6667 & 7,6667 & 4,0000 & 3,6667 & 8,3333 & 3,0000 & 4,0000 & 4,0000 & 8,3333 \\
\hline & 3,6667 & 4,6667 & 8,6667 & 8,0000 & 4,0000 & 3,6667 & 8,3333 & 3,3333 & 4,0000 & 4,3333 & 8,3333 \\
\hline & 4,6667 & 5,6667 & 9,6667 & 9,0000 & 5,0000 & 4,6667 & 9,3333 & 4,3333 & 5,0000 & 5,3333 & 9,3333 \\
\hline
\end{tabular}
answered by decision makers, the fuzzy decision matrix in Table 3 and the fuzzy weight of each criterion in Table 5 have been constructed.

\begin{tabular}{|c|c|c|c|c|c|c|c|c|c|c|c|}
\hline & C1 & $\mathrm{C} 2$ & C3 & $\mathrm{C4}$ & C5 & C6 & C7 & C8 & C9 & C10 & C11 \\
\hline & 0,2759 & 0,7931 & 0,6207 & 0,2759 & 0,3448 & 0,7931 & 0,7143 & 0,3214 & 0,2857 & 0,7857 & 0,2143 \\
\hline Alt & 0,3793 & 0,8966 & 0,7241 & 0,3793 & 0,4483 & 0,8966 & 0,8214 & 0,4286 & 0,3929 & 0,8929 & 0,3214 \\
\hline 1 & 0,3793 & 0,8966 & 0,7931 & 0,3793 & 0,4828 & 0,8966 & 0,8571 & 0,4286 & 0,3929 & 0,8929 & 0,3571 \\
\hline & 0,4828 & 1,0000 & 0,8966 & 0,4828 & 0,5862 & 1,0000 & 0,9643 & 0,5357 & 0,5000 & 1,0000 & 0,4643 \\
\hline Alterna & 0,7931 & 0,6207 & 0,2759 & 0,3448 & 0,7931 & 0,6897 & 0,3214 & 0,2857 & 0,7857 & 0,2143 & 0,3214 \\
\hline 2 & 0,8966 & 0,7241 & 0,3793 & 0,4483 & 0,8966 & 0,7931 & 0,4286 & 0,3929 & 0,8929 & 0,3214 & 0,4286 \\
\hline & 0,8966 & 0,7931 & 0,3793 & 0,4828 & 0,8966 & 0,8276 & 0,4286 & 0,3929 & 0,8929 & 0,3571 & 0,4286 \\
\hline
\end{tabular}

Table 3. The fuzzy decision matrix

The normalized fuzzy decision matrix is constructed as Table 4.

Table 4. Normalized fuzzy decision matrix 


\begin{tabular}{ccccccccccccc}
\hline \hline & & & & & & & & & & & & \\
& 1,0000 & 0,8966 & 0,4828 & 0,5862 & 1,0000 & 0,9310 & 0,5357 & 0,5000 & 1,0000 & 0,4643 & 0,5357 \\
\hline \multirow{2}{*}{$\begin{array}{c}\text { Alternative } \\
\mathbf{3}\end{array}$} & 0,6207 & 0,2759 & 0,3448 & 0,7931 & 0,6897 & 0,3103 & 0,2857 & 0,7857 & 0,2143 & 0,3214 & 0,3214 \\
& 0,7931 & 0,3793 & 0,4828 & 0,8966 & 0,8276 & 0,4138 & 0,3929 & 0,8929 & 0,3571 & 0,4286 & 0,4643 \\
& 0,8966 & 0,4828 & 0,5862 & 1,0000 & 0,9310 & 0,5172 & 0,5000 & 1,0000 & 0,4643 & 0,5357 & 0,5714 \\
\hline \multirow{3}{*}{ Alternative } & 0,2759 & 0,3448 & 0,7931 & 0,6897 & 0,3103 & 0,2759 & 0,7857 & 0,2143 & 0,3214 & 0,3214 & 0,7857 \\
$\mathbf{4}$ & 0,3793 & 0,4483 & 0,8966 & 0,7931 & 0,4138 & 0,3793 & 0,8929 & 0,3214 & 0,4286 & 0,4286 & 0,8929 \\
& 0,3793 & 0,4828 & 0,8966 & 0,8276 & 0,4138 & 0,3793 & 0,8929 & 0,3571 & 0,4286 & 0,4643 & 0,8929 \\
& 0,4828 & 0,5862 & 1,0000 & 0,9310 & 0,5172 & 0,4828 & 1,0000 & 0,4643 & 0,5357 & 0,5714 & 1,0000 \\
\hline
\end{tabular}

Table 5. Fuzzy weights of alternatives

\begin{tabular}{lcccc}
\hline & Alternative & Alternative & Alternative & Alternative \\
& $\mathbf{1}$ & $\mathbf{2}$ & $\mathbf{3}$ & $\mathbf{4}$ \\
\hline $\mathbf{C 1}$ & 0,1000 & 0,2000 & 0,2333 & 0,3333 \\
$\mathbf{C 2}$ & 0,4333 & 0,5000 & 0,5667 & 0,6667 \\
$\mathbf{C 3}$ & 0,4000 & 0,5000 & 0,5000 & 0,6000 \\
$\mathbf{C 4}$ & 0,7333 & 0,8333 & 0,8333 & 0,9333 \\
$\mathbf{C 5}$ & 0,7333 & 0,8333 & 0,8333 & 0,9333 \\
$\mathbf{C 6}$ & 0,5333 & 0,6333 & 0,6667 & 0,7667 \\
$\mathbf{C 7}$ & 0,7333 & 0,8333 & 0,8333 & 0,9333 \\
$\mathbf{C 8}$ & 0,7333 & 0,8333 & 0,8333 & 0,9333 \\
$\mathbf{C 9}$ & 0,7000 & 0,8000 & 0,8000 & 0,9000 \\
$\mathbf{C 1 0}$ & 0,7333 & 0,8333 & 0,8333 & 0,9333 \\
$\mathbf{C 1 1}$ & 0,7333 & 0,8333 & 0,8333 & 0,9333 \\
\hline
\end{tabular}

Then, the weighted normalized fuzzy decision matrix is obtained by multiplying the values in the normalized fuzzy decision matrix by the weight of each alternative.

Table 6. Weighted normalized fuzzy decision matrix

\begin{tabular}{|c|c|c|c|c|c|c|c|c|c|c|c|}
\hline & C1 & $\mathrm{C2}$ & C3 & $\mathrm{C4}$ & C5 & C6 & C7 & C8 & C9 & C10 & C11 \\
\hline & 0,0276 & 0,3437 & 0,2483 & 0,2023 & 0,2529 & 0,4230 & 0,5238 & 0,2357 & 0,2000 & 0,5762 & 0,1571 \\
\hline Alternative & 0,0759 & 0,4483 & 0,3621 & 0,3161 & 0,3736 & 0,5678 & 0,6845 & 0,3571 & 0,3143 & 0,7440 & 0,2679 \\
\hline \multirow[t]{2}{*}{1} & 0,0885 & 0,5080 & 0,3966 & 0,3161 & 0,4023 & 0,5977 & 0,7143 & 0,3571 & 0,3143 & 0,7440 & 0,2976 \\
\hline & 0,1609 & 0,6667 & 0,5379 & 0,4506 & 0,5471 & 0,7667 & 0,9000 & 0,5000 & 0,4500 & 0,9333 & 0,4333 \\
\hline \multirow{4}{*}{$\begin{array}{l}\text { Alternative } \\
\quad 2\end{array}$} & 0,0793 & 2690 & 03 & 0,2529 & 0,5816 & 0,3678 & 0,2357 & 0,2095 & 0,5500 & 0,1571 & 0,2357 \\
\hline & 0,1793 & 0,3621 & 0,1897 & 0,3736 & 0,7471 & 0,5023 & 0,3571 & 0,3274 & 0,7143 & 0,2679 & 0,3571 \\
\hline & 0,2092 & 0,4494 & 0,1897 & 0,4023 & 0,7471 & 0,5517 & 0,3571 & 0,3274 & 0,7143 & 0,2976 & 0,3571 \\
\hline & 0,3333 & 0,5977 & 0,2897 & 0,5471 & 0,9333 & 0,7138 & 0,5000 & 0,4667 & 0,9000 & 0,4333 & 0,5000 \\
\hline \multirow{4}{*}{$\begin{array}{c}\text { Alternative } \\
\mathbf{3}\end{array}$} & 0,0621 & 0,1195 & 0,1379 & 0,5816 & 0,5057 & 0,1655 & 0,2095 & 0,5762 & 0,1500 & 0,2357 & 0,2357 \\
\hline & 0,1448 & 0,1897 & 0,2241 & 0,7471 & 0,6609 & 0,2621 & 0,3274 & 0,7440 & 0,2571 & 0,3571 & 0,3571 \\
\hline & 0,1851 & 0,2149 & 0,2414 & 0,7471 & 0,6897 & 0,2759 & 0,3274 & 0,7440 & 0,2857 & 0,3571 & 0,3869 \\
\hline & 0,2989 & 0,3218 & 0,3517 & 0,9333 & 0,8690 & 0,3966 & 0,4667 & 0,9333 & 0,4179 & 0,5000 & 0,5333 \\
\hline \multirow{4}{*}{$\begin{array}{l}\text { Alternative } \\
\qquad 4\end{array}$} & 0,0276 & 0,1494 & 0,3172 & 0,5057 & 0,2276 & 0,1471 & 0,5762 & 0,1571 & 0,2250 & 0,2357 & 0,5762 \\
\hline & 0,0759 & 0,2241 & 0,4483 & 0,6609 & 0,3448 & 0,2402 & 0,7440 & 0,2679 & 0,3429 & 0,3571 & 0,7440 \\
\hline & 0,0885 & 0,2736 & 0,4483 & 0,6897 & 0,3448 & 0,2529 & 0,7440 & 0,2976 & 0,3429 & 0,3869 & 0,7440 \\
\hline & 0,1609 & 0,3908 & 0,6000 & 0,8690 & 0,4828 & 0,3701 & 0,9333 & 0,4333 & 0,4821 & 0,5333 & 0,9333 \\
\hline
\end{tabular}

After constructing the weighted normalized fuzzy decision matrix, the fuzzy positive ideal solution (FPIS) and fuzzy negative ideal solution (FNIS) values are determined as follows;

$A^{*}=[(1,1,1),(1,1,1),(1,1,1),(1,1,1),(1,1,1),(1,1,1)$, $(1,1,1),(1,1,1),(1,1,1),(1,1,1),(1,1,1)]$

$A^{-}=[(0,0,0),(0,0,0),(0,0,0),(0,0,0),(0,0,0),(0,0,0),(0,0,0)$, $(0,0,0),(0,0,0),(0,0,0),(0,0,0)]$
To determine the distance between FPIS and FNIS, vertex method is usedfor calculation. After the same procedure is realized for other alternatives and criteria, the distances of the alternatives to FPIS and FNIS according to the criteria are determined as in Table 7 and 8. 
Table 7. Distance between $A_{i}(\mathrm{i}=1, \ldots, 4)$ and $A^{*}$ respect toeach criterion

\begin{tabular}{lcccc}
\hline & $\boldsymbol{d}\left(\boldsymbol{A}_{\boldsymbol{1}}, \boldsymbol{A}^{*}\right)$ & $\boldsymbol{d}\left(\boldsymbol{A}_{2}, \boldsymbol{A}^{*}\right)$ & $\boldsymbol{d}\left(\boldsymbol{A}_{\mathbf{3}}, \boldsymbol{A}^{*}\right)$ & $\boldsymbol{d}\left(\boldsymbol{A}_{\mathbf{4}}, \boldsymbol{A}^{*}\right)$ \\
\hline $\mathbf{C 1}$ & 0,9130 & 0,8048 & 0,8317 & 0,9130 \\
$\mathbf{C 2}$ & 0,5216 & 0,5929 & 0,7918 & 0,7457 \\
$\mathbf{C 3}$ & 0,6224 & 0,8077 & 0,7650 & 0,5556 \\
$\mathbf{C 4}$ & 0,6844 & 0,6150 & 0,2772 & 0,3438 \\
$\mathbf{C 5}$ & 0,6150 & 0,2772 & 0,3438 & 0,6563 \\
$\mathbf{C 6}$ & 0,4290 & 0,4822 & 0,7296 & 0,7516 \\
$\mathbf{C} 7$ & 0,3232 & 0,6443 & 0,6734 & 0,2807 \\
C8 & 0,6443 & 0,6734 & 0,2807 & 0,7178 \\
C9 & 0,6861 & 0,3065 & 0,7286 & 0,6581 \\
C10 & 0,2807 & 0,7178 & 0,6443 & 0,6307 \\
C11 & 0,7178 & 0,6443 & 0,6307 & 0,2807 \\
\hline
\end{tabular}

Table 8. Distance between $A_{i}(\mathrm{i}=1, \ldots, 4)$ and $A^{-}$respect toeach criterion

\begin{tabular}{lcccc}
\hline & $\boldsymbol{d}\left(\boldsymbol{A}_{\boldsymbol{l}}, \boldsymbol{A}^{-}\right)$ & $\boldsymbol{d}\left(\boldsymbol{A}_{2}, \boldsymbol{A}^{-}\right)$ & $\boldsymbol{d}\left(\boldsymbol{A}_{3}, \boldsymbol{A}^{-}\right)$ & $\boldsymbol{d}\left(\boldsymbol{A}_{4}, \boldsymbol{A}^{-}\right)$ \\
\hline $\mathbf{C 1}$ & 0,1003 & 0,2198 & 0,1926 & 0,1003 \\
$\mathbf{C 2}$ & 0,5054 & 0,4367 & 0,2236 & 0,2739 \\
$\mathbf{C 3}$ & 0,3998 & 0,2049 & 0,2506 & 0,4644 \\
$\mathbf{C 4}$ & 0,3331 & 0,4076 & 0,7625 & 0,6934 \\
$\mathbf{C 5}$ & 0,4076 & 0,7625 & 0,6934 & 0,3615 \\
$\mathbf{C 6}$ & 0,6013 & 0,5481 & 0,2870 & 0,2647 \\
$\mathbf{C 7}$ & 0,7182 & 0,3744 & 0,3450 & 0,7600 \\
$\mathbf{C 8}$ & 0,3744 & 0,3450 & 0,7600 & 0,3053 \\
$\mathbf{C 9}$ & 0,3317 & 0,7302 & 0,2936 & 0,3599 \\
$\mathbf{C 1 0}$ & 0,7600 & 0,3053 & 0,3744 & 0,3928 \\
$\mathbf{C 1 1}$ & 0,3053 & 0,3744 & 0,3928 & 0,7600 \\
\hline
\end{tabular}

After these calculations, $d_{i}{ }^{*}$ and $d_{i}{ }^{-}$values are attained then closeness values are calculated for each alternative and then supplier performance rankings are obtained by fuzzy TOPSIS method.

Table 9. Distance coefficients of alternatives and ranking table

\begin{tabular}{lcccc}
\hline & Alternative & Alternative & Alternative & Alternative \\
& $\mathbf{1}$ & $\mathbf{2}$ & $\mathbf{3}$ & $\mathbf{4}$ \\
\hline $\boldsymbol{d}_{\boldsymbol{i}}{ }^{*}$ & 6,4376 & 6,5663 & 6,6969 & 6,5339 \\
$\boldsymbol{d}_{\boldsymbol{i}}{ }^{*}$ & 4,8371 & 4,7089 & 4,5756 & 4,7362 \\
$\boldsymbol{d}_{\boldsymbol{i}}{ }^{*}+\boldsymbol{d}_{\boldsymbol{i}}{ }^{-}$ & 11,2746 & 11,2753 & 11,2725 & 11,2701 \\
$\mathbf{C C}_{\boldsymbol{i}}$ & 0,4290 & 0,4176 & 0,4059 & 0,4202 \\
\hline
\end{tabular}

When the closeness coefficients of four alternatives are ranked from the largest to the smallest, it is seen that Alternative 1 is 0.4290 , Alternative 4 is 0.4202 , Alternative 2 is 0.4176 and Alternative 3 is 0.4059 . Under these circumstances, the firm must work with the Alternative 1 that has the highest coefficient.

\section{CONCLUSION}

During recent years, supply chain management is an integral part of business life. It is mostly accepted that a well-organized and managed supply chain is essential to company success and customer satisfaction. Many studies talk about the advantages of it. To construct long term solid relations with their suppliers can decrease purchasing costs, production costs for the firm and also boost customer services and financial position. In this way, firms strengthen their competitiveness. Therefore, supplier selection becomes significant issue for firms in today's global market conditions.

Supplier selection is a difficult and critical process because it includes many factors to determine the right supplier. If decision makers want to complete this selection process in an effective way, they should consider these factors for example, quality, delivery time, costs, flexibility, etc. In order to consider multiple factors, the system to be established for supplier selection should be a multi-criteria system. Thus, multi-criteria selection and evaluation systems have the opportunity to provide long-term competitive advantage. Generally, decision making process often contains uncertain conditions. Especially, the competition and uncertainty are intense in textile sector. The demand structure, fashion, market conditions are constantly unsteady. Under these conditions, to select the right supplier becomes a necessity in the sector. Assessing of possible suppliers under these circumstances is possible with fuzzy set theory. The use of linguistic variables in selecting supplier is beneficial when performance indicators of firms cannot be expressed by numerical values. Due to the fuzziness in group decision making process, fuzzy TOPSIS method, which is one of the multi-criteria decision-making models is used in the paper to deal with supplier selection problem of a textile manufacturing firm in Denizli.

In the paper, according to cost, payment due, discount, quality, healthy product, having quality certificate, delivery time, flexibility for changing in orders and delivery time, easy contact and problem solving capability criteria, the four firms supplying knitted fabric and sewing yarn to the company are evaluated by fuzzy TOPSIS method. The ratings and weights of the criteria are expressed by linguistic variables. Closeness coefficients are calculated for each supplier and then the supplier rankings are obtained. The supplier placed on the top at ranking list is considered as optimum supplier.

There are many suppliers in the textile sector with similar characteristics. To select a supplier for a order based manufacturing textile company requires precise evaluation. Minor differences in this process affect the company in different aspects, especially cost and quality. Therefore, the fuzzy TOPSIS method provides more accurate measurements in cases where similar scores occured like in this study.

Previous researches consider fuzzy TOPSIS method as a tool that can be used in supplier selection process. However, literature lacks empirical evidence when the suppliers perform very close to each other as in this study about selection in textile sector. At this point, decision makers can make very sensitive selection by means of fuzzy TOPSIS model. This study therefore fills that gap.

The main target of the study is to provide decision support in terms of firm managers. The method used in the paper assures more effective solution for supplier selection process in a fuzzy environment. Also, the study samples 
only one firm's supplier selection problem. For further studies, different methods can be used in not only the supplier selection problem but also other management decision problems for more firms.

\section{REFERENCES}

1. Ghodsypur SH, O’Brien C. 1998. A decision support system for supplier selection using an integrated analytic hierarchy process and linear programming, International Journal of Production Economics, 56-57, 199-212.

2. Shin H, Collier DA, Wilson DD. 2000. Supply management orientation and supplier/buyer performance, Journal of Operations Management, 18, 317-333.

3. Chen YJ. 2011. Structured Methodology for supplier selection and evaluation in a supply chain, Information Sciences, 181 (9), 16511670.

4. Ding H, Benyoucef L, Xie X. 2005. A simulation optimization methodology for supplier selection problem, International Journal of Computer Integrated Manufacturing, 18 (2-3), 210-224.

5. Monczka R, Trent R, Handfield R. 1998. Purchasing and supply chain management, South-Western College Publishing, New York.

6. Sarkis J, Talluri S. 2002. A model for strategic supplier selection, Journal of Supply Chain Management, 38 (1), 18-28.

7. Ho W, Xu X, Dey PK. 2010. Multi-criteria decision making approaches for supplier evaluation and selection: a literature review, European journal of Operational Research, 202 (1), 16-24.

8. De Boer L, Labro E, Morlacchi P. 2001. A review of methods supporting supplier selection, European Journal of Purchasing and Supply Management, 7 (2), 75-89.

9. Chen C-T, Lin C-T, Huang S-F. 2006. A fuzzy approach for supplier evaluation and selection in supply chain management, International Journal of Production Economics, 102 (2), 289-301.

10. Chen SJ, Hwang CL. 1992. Fuzzy Multiple Attribute Decision Making: Methods and Applications Springer-Verlag, Berlin.

11. Delgado M, Verdegay JL, Vila MA. 1992. Linguistic decisionmaking models, International Journal of Intelligent Systems, 7, 479492.

12. Hwang CL, Yoon K. 1981. Multiple attribute decision making, methods and applications: 186 (Lecture Notes in Economics and Mathematical Systems), Springer-Verlag, New York.

13. Herrera F, Herrera-Viedma E. 2000. Linguistic decision analysis: Steps for solving decision problems under linguistic information, Fuzzy Sets and Systems, 115, 67-82.

14. Herrera F, Herrera-Viedma E, Verdegay JL. 1996. A model of consensus in group decision making under linguistic assessments, Fuzzy Sets and Systems, 78, 73-87.

15. Chen CT. 2000. Extensions of the TOPSIS for group decision making under fuzzy environment, Fuzzy Sets and Systems, 114, 1-9.

16. Chen CT. 2001. A fuzzy approach to select the location of the distribution center, Fuzzy Sets and Systems, 118, 65-73.

17. Zadeh LA. 1975. The concept of a linguistic variable and its application to approximate reasoning, Information Sciences, 8, 199249

18. Cheng JZ, Chen PT, Yu HCD. 2005. Establishing a man access strategy for future broadband service: A Fuzzy MCDM analysis of SONET/SDH and Gigabit Ethernet, Technovation, 25 (5), 557-567.

19. Saghafian S, Hejazi R. 2005. Multi criteria group decision making using a modified Fuzzy TOPSIS procedure, Proceedings of the 2005 International Conference on Computational Intelligence for Modelling, Control and Automation, and International Conference on Intelligent Agents, Web Technologies and Internet Commerce CIMCA-IAWTIC'05, IEEE.(215-221), Vienna, Austria

20. Kleyle R, Korvin AD, Karim K. 1997. Investing in new companies in an unstable economic environment: A fuzzy set approach, Managerial Finance, 23 (6), 68-80.
21. Bellman RE, Zadeh LA. 1970. Decision-making in a fuzzy environment, Management Science, 17 (4), 141-164.

22. Cheng S, Chan CW, Huang GH. 2002. Using multiple criteria decision analysis for supporting decisions of solid waste management, Journal of Environment Science Health, 37 (6), 975-990.

23. Zouggari A, Benyoucef L. 2012. Simulation based fuzzy TOPSIS approach for group multi-criteria supplier selection problem, Engineering Applications of Artificial Intelligence, 25, 507-519.

24. Singh RK, Benyoucef L. 2012. Fuzzy logic and interval arithmeticbased topsis method for multicriteria reverse auctions, Service Science, 4 (2), 101-117.

25. Orji IJ, Wei S. 2014. A decision support tool for sustainable supplier selection in manufacturing firms, Journal of Industrial Engineering and Management, 7 (5), 1293-1315.

26. Kannan D, Jabbour ABL de Sousa, Jabbour C JC. 2014. Selecting green suppliers based on GSCM practices: Using fuzzy TOPSIS applied to a Brazilian electronics company, European Journal of Operational Research, 233 (2), 432-447.

27. Igoulalene I, Benyoucef L, Tiwari MK. 2015. Novel fuzzy hybrid multi-criteria group decision making approaches for the strategic supplier selection problem, Expert Systems with Applications, 42 (7), 3342-3356.

28. Wang JW, Cheng CH, Cheng HK. 2009. Fuzzy Hierarchical TOPSIS for supplier selection, Applied Soft Computing, 9, 377-386.

29. Razmi J, Songhori MJ, Khakbaz MH. 2009. An integrated fuzzy group decision making/fuzzy linear programming (FGDMLP) framework for supplier evaluation and order allocation. International Journal of Advanced Manufacturing Technology, 43 (5-6), 590-607.

30. Shahanaghi K, Yazdian SA. 2009. Vendor selection using a new fuzzy group TOPSIS approach. Journal of Uncertain Systems, 3 (3), 221-231.

31. Liao CN, Kao HP. 2011. An integrated fuzzy TOPSIS and MCGP approach to supplier selection in supply chain management, Expert Systems with Applications, 38, 10803-10811.

32. Li L, Zabinsky ZB. 2011. Incorporating uncertainty into a supplier selection problem, International Journal of Production Economics, 134 (2), 344-356

33. Rouyendegh BD, Saputro TE. 2014. Supplier selection using integrated fuzzy TOPSIS and MCGP: A case study, Procedia - Social and Behavioral Sciences, 116, 3957-3970.

34. Zavadskas EK, Turskis Z, Tamosaitiene J. 2008. Construction risk assessment of small scale objects by applying the TOPSIS method with attributes values determined at intervals, The $8^{\text {th }}$ International Conference Reliability and Statistic in Transportation and Communication, Latvia.

35. Hung CC, Chen LH. 2009. A fuzzy TOPSIS decision making model with entropy weight under intuitionistic fuzzy environment, Proceedings of the International Multi-Conference of Engineers and Computer Scientists IMECS, Hong Kong.

36. Wang YJ, Lee HS. 2007. Generalizing TOPSIS for fuzzy multiplecriteria group decision-making, Computers and Mathematics with Applications, 53, 1762-1772.

37. Bottani E, Rizzi A. 2006. A fuzzy TOPSIS methodology to support outsourcing of logistics services, Supply Chain Management: An International Journal, 11 (4), 294-308.

38. Zadeh LA. 1987. A fuzzy set theoretic interpretation of linguistic hedge, Fuzzy Sets and Applications: Selected Papers by Zadeh, L. A, Ed.: Yager RR, Ovchinnikov S, Tong RM, Nguyen HT. John Wiley\&Sons Publishing, Canada, 467-498. 
39. Gzeng GH, Huang JJ. 2011. Multiple Attribute Decision Making Methods and Applications. CRC Press, New York.

40. Hanss M. 2005. Applied fuzzy arithmetic: An introduction with engineering applications, Springer-Verlag, Berlin.

41. Sanchez J, Gomez AT. 2003. Applications of fuzzy regression in actuarial analysis, The Journal of Risk and Insurance, 70 (4), 665699.

42. Kaufmann A, Gupta MM. 1985. Introduction to Fuzzy Arithmetic: Theory and Applications, Van Nostrand Reinhold, New York.

43. Jahanshahloo GR, Lofti FH, Izadikhah M. 2006. Extension of the TOPSIS method for decision-making problems with fuzzy data, Applied Mathematics and Computation, 181, 1544-1551.

44. Monjezi M, Dehghani H, Singh TN, Sayadi AR, Gholinejad A. 2010 Application of TOPSIS method for selecting the most appropriate blast design, Arabian Journal of Geosciences, 5 (1), 95-101. 